\title{
Longitudinal increase in total lgE levels in patients with adult asthma: an association with poor asthma control
}

\author{
Akihiko Tanaka ${ }^{*}$, Megumi Jinno ${ }^{1}$, Kuniaki Hirai ${ }^{1}$, Yoshito Miyata ${ }^{1}$, Hiroko Mizuma ${ }^{1}$, Munehiro Yamaguchi ${ }^{1}$, \\ Shin Ohta', Yoshio Watanabe', Mayumi Yamamoto', Shintaro Suzuki', Takuya Yokoe', Mitsuru Adachi \\ and Hironori Sagara ${ }^{1}$
}

\begin{abstract}
Background: Immunoglobulin (Ig) E is well-known to play a critical role in allergic diseases. We investigated the association between longitudinal change in total IgE level and the asthma control in patients with adult asthma.

Methods: For this retrospective study, 154 patients with asthma aged 21-82 years were recruited from the allergy and pulmonary units of the Showa University Hospital. Data on longitudinal changes in IgE over the preceding 10 years were collected and logarithmically transformed. Associations between longitudinal change in IgE and clinical characteristics including asthma control test (ACT) score, asthma control, pulmonary function test, and antigen specific IgE, were assessed.

Results: Patients with increased IgE tended to have significantly higher mean age, more episodes of acute exacerbation within a year, lower ACT scores, and used oral corticosteroids more frequently than those with decreased or unchanged IgE. The prevalence of uncontrolled asthma was higher in patients with increased IgE than in those with decreased or unchanged IgE. Mean \%FEV ${ }_{1}$ and $\mathrm{FEV}_{1 \%}$ were lower in patients with increased IgE than in those with decreased or unchanged IgE. Moreover, the prevalence of Aspergillus-specific IgE was higher in patients with increased IgE than in those with decreased or unchanged IgE.
\end{abstract}

Conclusions: These data suggest that a longitudinal increase in total IgE is associated with both poor asthma control and Aspergillus-specific lgE in patients with adult asthma.

Keywords: IgE, Longitudinal change, Severe asthma, Aspergillus, house dust mite

\section{Introduction}

Immnoglobulin E (IgE), the fifth and last immunoglobulin to be identified, was first reported in 1966 [1]. Measurements of total and antigen-specific IgE are helpful for diagnosing allergic diseases. IgE is a critical factor for the development of bronchial hyperresponsiveness in asthmatics [2]. Epidemiological studies have shown that total IgE level is higher in patients with asthma, particularly in children, than in non-asthmatics [3-5]. Recently, a longitudinal analysis of European

\footnotetext{
*Correspondence: tanakaa@med.showa-u.ac.jp

'Department of Internal Medicine, Division of Allergy and Respiratory Medicine, Showa University, School of Medicine, 1-5-8 Hatanodai, Shinagawa-ku, Tokyo 142-8666, Japan

Full list of author information is available at the end of the article
}

Community Respiratory Health Survey data showed that total IgE was associated with new-onset asthma among atopics [6]. Meanwhile, the association between total IgE level and non-atopic asthma remains controversial $[7,8]$.

Total IgE level is higher in children with severe asthma than in those with mild to moderate asthma [9]. In The Epidemiology and Natural History of Asthma: Outcomes and Treatment Regimens study, an association between a high level of total IgE and asthma severity was observed among younger subjects with difficult-to-treat or severe asthma $[10,11]$. In a study conducted by de Marco et al., a high level of IgE was a strong predictor of moderate-to-severe asthma among 856 European adult patients with asthma [12]. However, recent global 
multicenter clinical trials, such as the Severe Asthma Research Program [13] and the European Network For Understanding Mechanisms of Severe Asthma [14], showed no correlation between asthma severity and levels of total and antigen-specific IgE, raising suspicion that IgE may not play a role in the deterioration of asthma control in patients with adult asthma. In recent years, a recombinant humanized monoclonal anti-IgE antibody, omalizumab, has been used in patients with allergic severe asthma $[15,16]$. Its effectiveness reminds us of the functional importance of IgE in severe asthma.

In general, serum total IgE concentration seems to peak in early adolescence and decrease with age [17-19]. However, longitudinal change in IgE is heterogeneous among patients with adult asthma. Although there have been several large-scale cross-sectional studies of total $\operatorname{IgE}$ and antigen-specific IgE $[20,21]$, only one multicenter study has assessed longitudinal change in total IgE and prevalence of IgE sensitization in the same population [22]. This study showed an overall decrease in total IgE over 10 years, in line with previous cross-sectional studies [17-19]. Meanwhile, few studies have interpreted longitudinal change in total IgE in individuals.

The aim of the present study was to investigate the association between longitudinal change in total IgE and asthma control to elucidate the role of longitudinal change in IgE in patients with asthma.

\section{Methods}

\section{Study design}

This was a retrospective study conducted in the allergy and pulmonary units of the Showa University Hospital, Tokyo, Japan, between January 2011 and December 2012. The study protocol was approved by the Showa University ethics committee and written informed consent was obtained.

\section{Study subjects}

Out of 854 asthmatic patients, we recruited 154 patients, whose longitudinal changes in total IgE in the preceding $10( \pm 2)$ years could be obtained. All patients had been regularly followed at Showa University Hospital. Individuals with chronic obstructive pulmonary disease (COPD) or other lung disease, smoking history greater than 20 pack-years, being treated with omalizumab, vocal cord dysfunction, or neurological disease were excluded. No participants, even those who had high IgE level, had parasitic infections. Asthma was diagnosed based on cough, breathlessness or dyspnea, and demonstration of airflow variability. The latter was determined according to a reversible airflow limitation that represented an increase in forced expiratory volume in $1 \mathrm{~s}\left(\mathrm{FEV}_{1}\right)$ of $12 \%$ or $200 \mathrm{~mL}$ after the inhalation of salbutamol.

\section{Data collection}

Baseline data including medical history, Asthma Control Test (ACT) score, spirometry, fractional exhaled nitric oxide (FeNO), percent peripheral eosinophils, total and specific IgE [Dermatophagoides pteronissinus (house dust mite: HDM), Cryptomeria japonica (cedar), Ambrosia artemisiifolia (ragweed), Candida albicans (candida), Aspergillus fumigatus (aspergillus), Alternaria alternata (alternaria), dog dander, cat dander, Bombyx mori (moth), and Blatta orientalis (cockroach)] were collected at enrollment. The definition of atopic type was being positive to crude house dust-specific IgE.

Asthma control was assessed using the validated Japanese version of the ACT. Patients were subjectively evaluated for the degree of impairment caused by their asthma during the preceding 4 weeks by responding to five questions using a five-point scale.

Spirometry was performed using an AS-302 spirometer (Minato Medical Science Co., Ltd., Osaka, Japan) in accordance with American Thoracic Society/European Respiratory Society guidelines $[23,24]$ to determine $\mathrm{FEV}_{1}$, forced vital capacity (FVC), and $\mathrm{FEV}_{1} / \mathrm{FVC}\left(\mathrm{FEV}_{1 \%}\right)$. The highest value from three technically satisfactory attempts was recorded. $\mathrm{FEV}_{1}$ and $\mathrm{FVC}$ values were expressed as a percentage of the predicted value.

FeNO was measured by a portable device (NIOX MINO, Aerocrine AB, Solna, Sweden) at an expiratory flow rate of $50 \mathrm{~mL} / \mathrm{s}$ for $10 \mathrm{~s}$.

Serum total IgE levels, measured with a fluorescent enzyme immunoassay (ImmunoCAP-FEIA, Phadia, Freiburg, Germany) were transformed logarithmically to normalize their distribution. A zero was replaced with a value half of the lowest value observed before log transformation. Antigen-specific IgE was also measured with ImmunoCAP-FEIA, and levels higher than class 2 were considered as positive. The longitudinal change in total $\operatorname{IgE}(\triangle \mathrm{IgE})$ was calculated as $\log$ total $\operatorname{IgE}$ at present - log total IgE 10 years ago. An increase or decrease in total IgE was arbitrarily designated as a variation of $>0.15 \log 10 \mathrm{kU} / \mathrm{L}$.

\section{Statistical analyses}

Results were expressed as mean \pm SD for continuous variables. FeNO values were transformed logarithmically to normalize their distribution. All analyses were performed using JMP version 10 (SAS Institute Inc., Cary, NC, USA). Differences in the continuous variables between groups were tested by analysis of variance (ANOVA); if the differences between groups were significant, comparisons were made by unpaired $t$-test. Categorical variables were analyzed with $X^{2}$ tests. A value of $P<0.05$ was considered significant for all statistical assessments. 


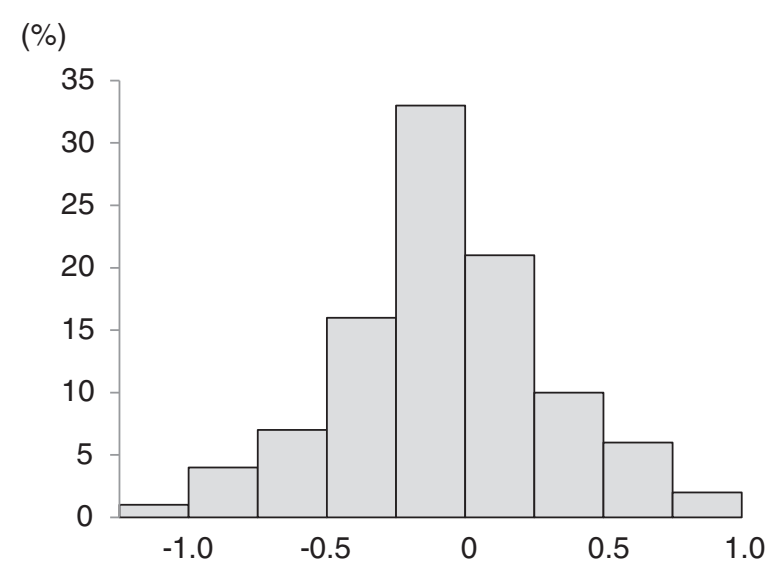

Figure 1 Distribution of the longitudinal change in IgE across 0.25 in patients with adult asthma.

\section{Results}

\section{Background}

One hundred and fifty-four patients with asthma with a median age of 62.5 years (range 21-82) were included. The mean BMI was $23.1 \pm 3.6$, and 62 patients (40.3\%) were men. Thirteen patients $(8.4 \%)$ were current smokers, and 31 patients (20.1\%) were ex-smokers at the time of enrollment. The mean ACT score and FeNO were $20.7 \pm 3.7$ and $51.3 \pm 42.9 \mathrm{ppb}$, respectively. In the pulmonary function test, the mean FVC and
FEV $_{1}$ were $2.5 \pm 0.9 \mathrm{~L}$ (\%FVC: $88.2 \pm 19.3 \%$ ), and $1.8 \pm$ $0.8 \mathrm{~L}\left(\% \mathrm{FEV}_{1}: 75.0 \pm 23.0 \%\right)$, respectively.

Mean total IgE was $2.43 \pm 0.65 \log _{10} \mathrm{kU} / \mathrm{L} 10$ years ago and $2.37 \pm 0.66 \log _{10} \mathrm{kU} / \mathrm{L}$ at the time of the study. An increase or decrease in IgE was arbitrarily designated as a variation of $>0.15 \log _{10} \mathrm{kU} / \mathrm{L}$. Figure 1 displays the distribution of patients according to longitudinal change in IgE.

Demographic details for the patient population are shown in Table 1. No significant differences were observed in gender, BMI, percent adult onset, smoking status, atopic type, pet ownership, allergic rhinitis, pollinosis, eosinophils, or FeNO between the groups. However, there were significant differences in age, prevalence of patients treated at levels higher than Step 4, frequency of use of on-demand oral corticosteroid (OCS), episode of acute exacerbation within a year, and pre-IgE level between the groups. Mean age was significantly higher for patients with increased IgE than for those with decreased or unchanged IgE. However, in this study, there was no significant correlation between $\triangle \mathrm{IgE}$ and age (data not shown). Mean pre-IgE level was significantly lower in patients with increased IgE than in patients with decreased IgE.

\section{ACT}

To identify patients with poor asthma control, several tools can be used globally, one of which is ACT. This test comprises five questions to assess activity limitation,

Table 1 Subject demographics and patient characteristics

\begin{tabular}{|c|c|c|c|c|}
\hline & Decrease $(N=63)$ & No change $(\mathrm{N}=50)$ & Increase $(\mathrm{N}=41)$ & $p$ value \\
\hline Age (years) & $61.3 \pm 14.6^{*}$ & $59.5 \pm 13.7^{* *}$ & $67.8 \pm 11.2$ & $0.011+$ \\
\hline Gender (M/F) & $27 / 36$ & $21 / 29$ & $14 / 27$ & NS \\
\hline BMI & $23.7 \pm 0.4$ & $23.2 \pm 0.5$ & $22.1 \pm 0.5$ & NS \\
\hline Adult onset, n (\%) & $45(71.4)$ & $39(78.0)$ & $34(82.9)$ & NS \\
\hline Smoking status, never/ex/current (\%) & 46/12/5 (73.0/19.1/7.9) & $38 / 8 / 4 /(76.0 / 16.0 / 8.0)$ & 26/11/4/ (63.4/26.8/9.8) & NS \\
\hline Atopic type, n (\%) & $42(66.6)$ & $30(60.0)$ & $21(51.2)$ & NS \\
\hline Pet owner, n (\%) & $16(25.4)$ & $11(22.0)$ & $9(21.9)$ & NS \\
\hline Allergic rhinitis, n (\%) & $30(47.6)$ & $23(46.0)$ & $15(36.5)$ & NS \\
\hline Pollinosis, n (\%) & $27(42.8)$ & $24(48.0)$ & $21(51.2)$ & NS \\
\hline Treatment with higher than Step 4, (\%) & $17(26.9)$ & $14(28.0)$ & $20(48.78)$ & $0.045 \neq$ \\
\hline OCS on demand, none/rare/frequent (\%) \|I & $35 / 22 / 6(55.6 / 34.9 / 9.5)$ & $40 / 8 / 2(80.0 / 16.0 / 4.0)$ & 23/12/6 (56.1/29.3/14.6) & $0.046 \neq$ \\
\hline Episode of acute exacerbation within a year & $15(23.8)$ & $7(14.0)$ & $15(36.6)$ & $0.042 \ddagger$ \\
\hline Eosinophils, \% of WBC & $5.45 \pm 0.48$ & $4.75 \pm 0.54$ & $5.49 \pm 0.60$ & NS \\
\hline Pre-lgE, IU/L & $1020.6 \pm 1654.8$ & $873.5 \pm 2018.3$ & $695.8 \pm 2555.9$ & - \\
\hline Pre-lgE (log-transforn), IU/L & $2.59 \pm 0.08^{* * *}$ & $2.40 \pm 0.09$ & $2.22 \pm 0.10$ & $0.014+$ \\
\hline FeNO, ppb & $52.2 \pm 5.6$ & $50.7 \pm 6.3$ & $50.5 \pm 7.0$ & NS \\
\hline
\end{tabular}

Values are Mean \pm SDs or medians (\%).

$t p$ values given for the ANOVA.

$\neq p$ values given for the Pearson $x^{2}$ test.

${ }^{*} \mathrm{p}<0.05$ or ${ }^{* *} \mathrm{p}<0.01$ or ${ }^{* * *} \mathrm{p}<0.001$ versus increase.

I Treatment step is based on the Global Initiative for Asthma (GINA) guideline.

II none: never, rare: less than once a month, frequent: once or more a month.

OCS: oral corticosteroids. 


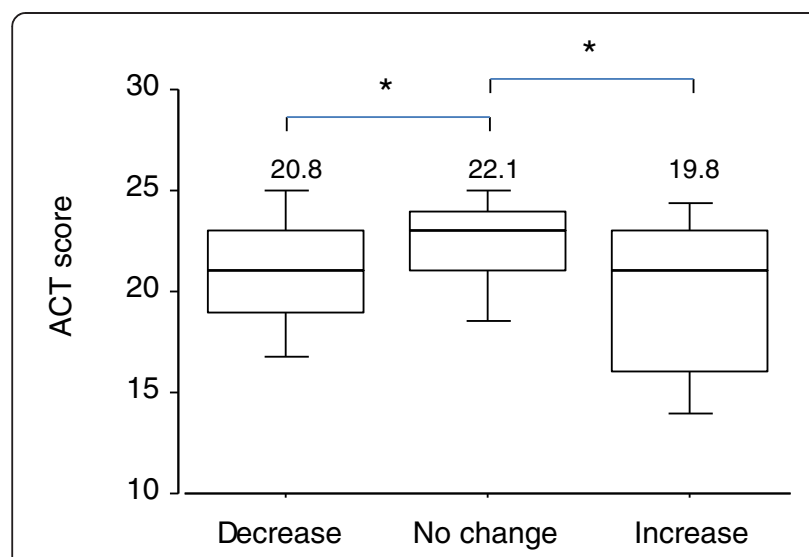

Figure 2 ACT scores of patients with asthma. Mean ACT scores are shown on the top of the bars. ACT comprises five questions to assess activity limitation, shortness of breath, nighttime symptoms, use of rescue medication, and patient's overall rating of asthma control over the previous 4 weeks. *: Significant difference $(P<0.01)$ versus the unchanged IgE group, as determined by $t$-test following a one-way analysis of variance (ANOVA).

shortness of breath, nighttime symptoms, use of rescue medication, and the patient's overall rating of asthma control over the previous 4 weeks. Mean ACT score was significantly lower for patients with increased IgE (Figure 2, $\mathrm{P}=0.006$ ) and for patients with decreased IgE (Figure 2, $\mathrm{P}=0.007$ ) than for patients with no change in IgE.

\section{Control level}

The Global Initiative for Asthma (GINA) guidelines, the most widely used asthma guidelines in the world, emphasize the importance of evaluating asthma control rather than asthma severity. The GINA guidelines provide a categorical scale for assessing asthma control, consisting of well-controlled, partly controlled, or uncontrolled asthma [25]. Asthma control levels of the patients in this study are shown in Figure 3. Significant differences were observed between the groups $(\mathrm{P}=0.014)$. In particular, $34.1 \%$ of the patients with increased IgE had uncontrolled asthma, compared with $12.7 \%$ and $10.0 \%$ of patients with decreased and unchanged IgE, respectively.

\section{Pulmonary function test}

Lung function, as an assessment of variable airway obstruction, is an objective of asthma control. There was no significant difference in \%FVC between the groups (Figure 4A). In contrast, significant differences were observed in $\% \mathrm{FEV}_{1}$ and $\mathrm{FEV}_{1 \%}$. The patients with increased IgE had lower $\% \mathrm{FEV}_{1}$ than did the patients with no change in IgE (Figure $4 \mathrm{~B}, \mathrm{P}=0.006$ ), and lower $\mathrm{FEV}_{1 \%}$ than patients with decreased or unchanged IgE (Figure 4C, $\mathrm{P}<0.001$ ).

\section{$\lg$ E specific to inhaled antigens}

The prevalence of IgE specific to inhaled antigens is shown in Table 2. There was no significant difference between the three groups for HDM, cedar, ragweed, candida, alternaria, dog dander, cat dander, moth, and cockroach. In contrast, a significant difference was found for aspergillus $(\mathrm{P}<0.001)$. The patients with increased $\operatorname{IgE}$ had a higher prevalence of aspergillus sensitization than other groups. In addition, patients who were positive to aspergillus-specific $\operatorname{IgE}$ had higher $\Delta \mathrm{IgE}$ than patients who were negative for aspergillus-specific IgE $(0.123 \pm$ 0.36 vs $-0.098 \pm 0.41, \mathrm{P}=0.008)$.

\section{Discussion}

In the present study, we found that patients with a longitudinal increase in total IgE used on-demand OCS

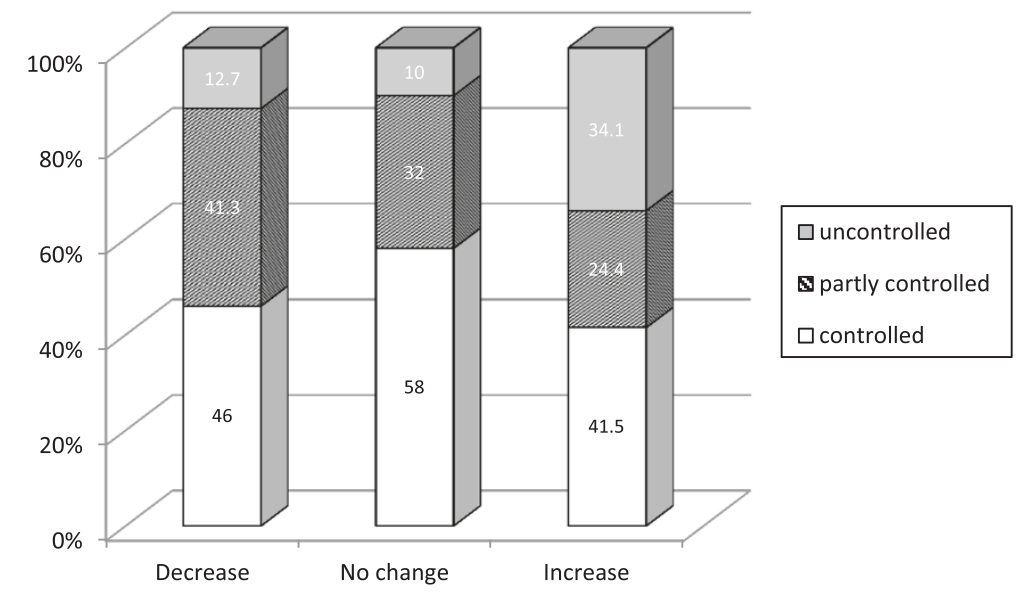

Figure 3 Distribution of patients according to asthma control level. Asthma was identified as controlled, partly controlled or uncontrolled based on the categorical scale of Global Initiative for Asthma. Low data were shown in the bars. A $x^{2}$ test demonstrated a significant difference between the groups $(P=0.014)$. 


\section{(A)}

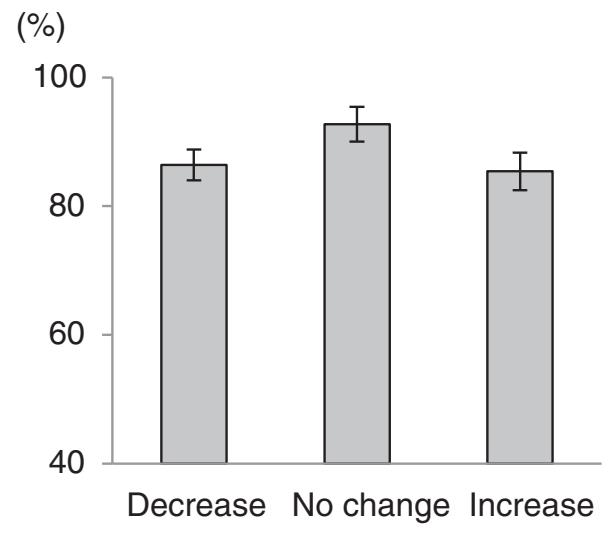

(B)

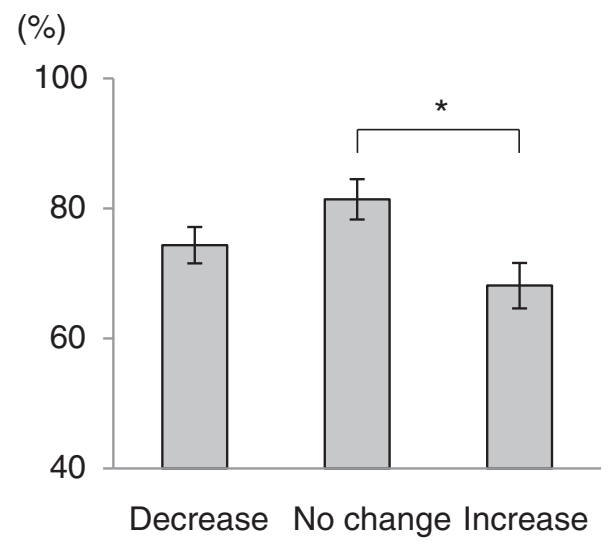

(C)

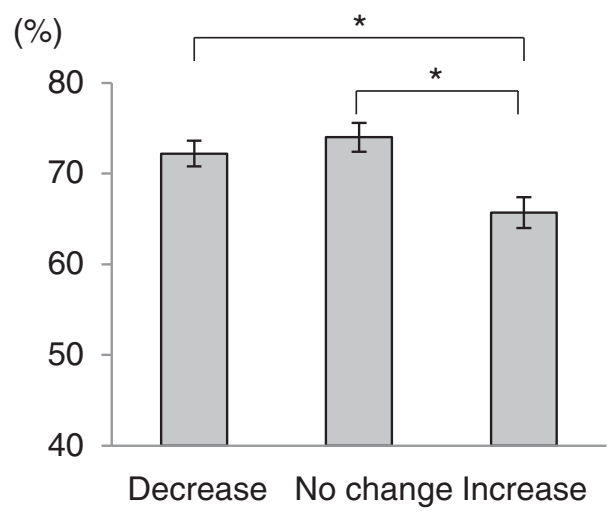

Figure 4 Pulmonary function tests in patients with asthma. $\% F V C(A), \% F V_{1}$ (B), and $\mathrm{FEV}_{1 \%}$ (C) are shown. The highest value from three technically satisfactory attempts was recorded. *: Significant difference $(P<0.01)$ versus the indicated group, as determined by t-test following a one-way ANOVA.

more frequently, were more likely to have been treated at levels above Step 4, had more episode of acute exacerbation within a year, had lower ACT scores, and were more likely to have uncontrolled asthma than patients with a longitudinal decrease in IgE or no change in IgE. In addition, more airway obstructions were observed among patients with a longitudinal increase in IgE. These results suggest that a longitudinal increase in IgE is associated with poor asthma control. To our knowledge, this is the first study to investigate the clinical role of longitudinal change in total IgE in patients with adult asthma and to demonstrate the possible association between a longitudinal increase in IgE and poor control of adult asthma. Recent global trials showed no association between absolute IgE levels and asthma severity in patients with adult asthma $[13,14]$. Considering these previous global trials, our interpretation of the present study is that a measurement of longitudinal change but not absolute value in total IgE predicts, to some extent, asthma control in clinical practice.

Longitudinal changes in IgE vary considerably among individual in patients with adult asthma, as shown in Figure 1. We stratified adult asthma patients according to the longitudinal change in IgE to identify characteristics of patients with increased IgE. We found that the mean age of patients with a longitudinal increase in IgE was higher than that of patients with a decrease or no change in IgE, suggesting that an increase in total IgE is associated with aging among patients with uncontrolled asthma. Previous epidemiological studies showed that mean total IgE levels in patients with asthma decreased with age $[20,26]$. The participants in these studies were younger, (mostly less than 60 ) than those who enrolled in our study. In addition, these studies were crosssectional rather than longitudinal. Thus, the results of these studies cannot be easily compared with our data. Further investigation of longitudinal changes in total and antigen-specific IgE in adult asthma, particularly over the age of 60 , is needed.

Previous studies have shown that males and current smokers have higher IgE levels than females and noncurrent smokers, respectively [27-29]. In the current study, there were no significant differences in gender or current smoking status between three groups (Table 1). The reasons for this are still unclear, but one possible reason for the lack of a difference in smoking status is that participants whose smoking history was greater than 20 pack-years were excluded for exclusion of COPD.

The total IgE level reflects both specific and unspecific IgE. Matricardi et al. followed total and allergenspecific IgE levels in children from birth to 13 years of age [30]. This study revealed that the evolution of total IgE was extremely heterogeneous but was parallel with that of allergen-specific IgE from the age of 5 onwards. Furthermore, Carsin et al. demonstrated that total IgE level is related to new-onset asthma, but this association is 
Table 2 Numbers and percentages of patients positive for antigen-specific IgE

\begin{tabular}{|c|c|c|c|c|c|c|c|c|c|c|}
\hline & HDM & cedar & ragwood & candida & Aspergillus* & alter-naria & dog dander & cat dander & moth & cock-roach \\
\hline decrease $(N=63)$ & 42/63 (66.6\%) & 29/63 (46.0\%) & $5 / 63(7.9 \%)$ & 11/63 (17.4\%) & 4/63 (6.3\%) & $3 / 63(4.7 \%)$ & 11/47 (23.4\%) & 11/47 (23.4\%) & 13/50 (26.0\%) & $6 / 47(12.7 \%)$ \\
\hline no change $(N=50)$ & $31 / 50(62.0 \%)$ & $32 / 50(64.0 \%)$ & $1 / 50(2.0 \%)$ & $8 / 50$ (16.0\%) & $5 / 50(10.0 \%)$ & $1 / 50(2.0 \%)$ & 7/33 (21.2\%) & $8 / 33$ (24.2\%) & 10/34 (29.4\%) & $4 / 22(18.1 \%)$ \\
\hline increase $(N=41)$ & 22/41 (53.6\%) & 24/41 (58.5\%) & 6/41 (14.6\%) & 10/41 (24.3\%) & 15/41 (36.5) & $5 / 41(12.1 \%)$ & 5/32 (15.6\%) & 5/32 (15.6\%) & 7/31 (22.5\%) & $6 / 29(31.0 \%)$ \\
\hline
\end{tabular}


almost entirely explained by specific IgE [31]. In the present study, specific IgE to HDM was the most prevalent, followed by cedar-specific IgE. The prevalence of specific IgE to HDM and cedar did not differ between groups, indicating that these antigen-specific IgE did not contribute to the longitudinal increase in total IgE. The prevalence of specific IgE to fungi, such as aspergillus and alternaria, was higher in the increased IgE group than in the other two other groups. In particular, significant difference was observed for aspergillus-specific IgE. This suggests that specific IgE to fungi, especially aspergillus, might have contributed to the longitudinal increase in total IgE and also to poor control in the increased IgE group. This is clinically plausible, since sensitization to aspergillus is one of the factors that results in difficult-to-treat asthma, such as allergic bronchopulmonary aspergillosis (ABPA) and severe asthma with fungal sensitization (SAFS) [32]. In addition, a previous study showed that specific IgE to Aspergillus fumigatus contributed to an increased risk of adult onset of asthma [33]. To the best of our knowledge, this is the first report indicating the association between aspergillusspecific IgE and a longitudinal increase in total IgE in patients with adult asthma.

There are several limitations to our study. First, although we showed that patients with increased IgE had a higher prevalence of aspergillus-specific IgE than patients with decreased or unchanged IgE, a longitudinal change in aspergillus-specific IgE could not be shown. Thus, to demonstrate directly the contribution of aspergillus-specific IgE to the increase in total IgE and poor control of asthma, we should assesse the association between longitudinal change in aspergillus-specific IgE and longitudinal change in total IgE and control levels.

Second, the treatments of patients were not taken into consideration in this study. The treatments of all patients enrolled in this study have changed, usually a number of times, during the past 10 years. Therefore, we could not account for the treatments in our analysis. It remains unclear how treatments affect longitudinal changes in total IgE and antigen-specific IgE.

In conclusion, this is the first study to investigate the clinical roles of longitudinal change in serum total IgE in patients with asthma. We demonstrated that longitudinal increase in total IgE is associated with poor asthma control and a higher prevalence of aspergillus-specific IgE in patients with adult asthma, suggesting a significant contribution of IgE in the pathophysiology of severe asthma. Further prospective analysis is needed to validate our data.

\section{Abbreviations}

ACT: Asthma control test; ANOVA: Analysis of variance; BMI: Body mass index; Der p: Dermatophagoides pteronyssius; ECRHS: European community respiratory health survey; ENFUMOSA: European network for understanding mechanisms of severe asthma; FEIA: Fluorescent enzyme immunoassay;

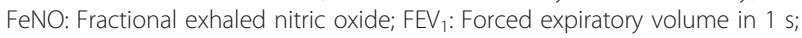
FVC: Forced vital capacity; GINA: Global initiative for asthma; Ig: Immunoglobulin; SAFS: Severe asthma with fungal sensitization; SARP: Severe asthma research program; TENOR: The epidemiology and natural history of asthma: outcomes and treatment regimens.

\section{Competing interests}

The authors declare that they have no competing interests.

\section{Authors' contributions}

AT performed the major part of the analysis, contributed to the interpretation of the results and drafted the manuscript. MJ, KH, YM, HM, MY, SO, YW, MY, and SS contributed to the analysis of the study, and supported the development of the manuscript. TY and HS participated in the interpretation of the results, and contributed to the development of the manuscript. MA conceived the outline of the current analysis, and supervised its completion. All authors agreed with the final draft of the manuscript.

\section{Acknowledgments}

The authors thank Miss Kyoko Inui and Miss Manami Matsuda for their excellent assistance in data collection and analysis.

\section{Support statement}

This work was supported by Health Labor Sciences Research Grants from the Japanese Ministry of Health, Labour and Welfare.

\section{Author details}

${ }^{1}$ Department of Internal Medicine, Division of Allergy and Respiratory Medicine, Showa University, School of Medicine, 1-5-8 Hatanodai, Shinagawa-ku, Tokyo 142-8666, Japan. ²Department of Allergy, Sanno Hospital, Clinical Research Centers for Medicine, International University of Health and Welfare, Tokyo, Japan.

Received: 13 September 2014 Accepted: 3 November 2014 Published online: 20 November 2014

\section{References}

1. Ishizaka K, Ishizaka T: Physicochemical properties of reaginic antibody. 1. Association of reaginic activity with an immunoglobulin other than gammaA- or gammaG-globulin. J Allergy 1966, 37:169-185.

2. Wu LC, Zarrin AA: The production and regulation of lgE by the immune system. Nat Rev Immunol 2014, 14:247-259.

3. Criqui MH, Seibles JA, Hamburger RN, Coughlin SS, Gabriel S: Epidemiology of immunoglobulin E levels in a defined population. Ann Allergy 1990, 64:308-313.

4. Burrows B, Martinez FD, Halonen M, Barbee RA, Cline MG: Association of asthma with serum IgE levels and skin-test reactivity to allergens. $N$ Engl J Med 1989, 320:271-277.

5. Pinart M, Benet M, Annesi-Maesano I, von Berg A, Berdel D, Carlsen KC, Carlsen KH, Bindslev-Jensen C, Eller E, Fantini MP, Lenzi J, Gehring U, Heinrich J, Hohmann C, Just J, Keil T, Kerkhof M, Kogevinas M, Koletzko S, Koppelman GH, Kull I, Lau S, Melén E, Momas I, Porta D, Postma DS, Rancière F, Smit HA, Stein RT, Tischer CG, et al: Comorbidity of eczema, rhinitis, and asthma in IgE-sensitised and non-lgE-sensitised children in MeDALL: a population-based cohort study. Lancet Respir Med 2014, 2:131-140.

6. Antó JM, Sunyer J, Basagaña X, Garcia-Esteban R, Cerveri I, de Marco R, Heinrich J, Janson C, Jarvis D, Kogevinas M, Kuenzli N, Leynaert B, Svanes C, Wjst M, Gislason T, Burney P: Risk factors of new-onset asthma in adults: a population-based international cohort study. Allergy 2010, 65:1021-1030.

7. Beeh KM, Ksoll M, Buhl R: Elevation of total serum immunoglobulin E is associated with asthma in nonallergic individuals. Eur Respir J 2000, 16:609-614.

8. Gergen PJ, Arbes SJ, Calatroni A, Mitchell HE, Zeldin DC: Total IgE levels and asthma prevalence in the US population: results from the National Health and Nutrition Examination Survey 2005-2006. J Allergy Clin Immunol 2009, 124:447-453.

9. Siroux V, Oryszczyn MP, Paty E, Kauffmann F, Pison C, Vervloet D, Pin I: Relationships of allergic sensitization, total immunoglobulin $\mathrm{E}$ and blood 
eosinophils to asthma severity in children of the EGEA Study. Clin Exp Allergy 2003, 33:746-751.

10. Borish L, Chipps B, Deniz Y, Gujrathi S, Zheng B, Dolan CM, Group TS: Total serum IgE levels in a large cohort of patients with severe or difficult-totreat asthma. Ann Allergy Asthma Immunol 2005, 95:247-253.

11. Haselkorn T, Szefler SJ, Simons FE, Zeiger RS, Mink DR, Chipps BE, Borish L, Wong DA, Group TS: Allergy, total serum immunoglobulin E, and airflow in children and adolescents in TENOR. Pediatr Allergy Immunol 2010, 21:1157-1165.

12. de Marco R, Marcon A, Jarvis D, Accordini S, Almar E, Bugiani M, Carolei A, Cazzoletti L, Corsico A, Gislason D, Gulsvik A, Jõgi R, Marinoni A, MartínezMoratalla J, Pin I, Janson C, European Community Respiratory Health Survey Therapy Group: Prognostic factors of asthma severity: a 9-year international prospective cohort study. J Allergy Clin Immunol 2006, 117:1249-1256.

13. Moore WC, Bleecker ER, Curran-Everett D, Erzurum SC, Ameredes BT, Bacharier L, Calhoun WJ, Castro M, Chung KF, Clark MP, Dweik RA, Fitzpatrick AM, Gaston B, Hew M, Hussain I, Jarjour NN, Israel E, Levy BD, Murphy JR, Peters SP, Teague WG, Meyers DA, Busse WW, Wenzel SE, National Heart L, Blood Institute's Severe Asthma Research Program: Characterization of the severe asthma phenotype by the national heart, lung, and blood institute's severe asthma research program. J Allergy Clin Immunol 2007, 119:405-413.

14. The ENFUMOSA cross-sectional European multicentre study of the clinical phenotype of chronic severe asthma. European network for understanding mechanisms of severe asthma. Eur Respir J 2003, 22:470-477.

15. Humbert M, Beasley R, Ayres J, Slavin R, Hébert J, Bousquet J, Beeh KM, Ramos S, Canonica GW, Hedgecock S, Fox H, Blogg M, Surrey K: Benefits of omalizumab as add-on therapy in patients with severe persistent asthma who are inadequately controlled despite best available therapy (GINA 2002 step 4 treatment): INNOVATE. Allergy 2005, 60:309-316.

16. Lafeuille MH, Gravel J, Zhang J, Gorsh B, Figliomeni M, Lefebvre P: Association between consistent omalizumab treatment and asthma control. J Allergy Clin Immunol Pract 2013, 1:51-57.

17. Wittig HJ, Belloit J, De Fillippi I, Royal G: Age-related serum immunoglobulin $E$ levels in healthy subjects and in patients with allergic disease. J Allergy Clin Immunol 1980, 66:305-313.

18. Grundbacher FJ, Massie FS: Levels of immunoglobulin $G, M, A$, and $E$ at various ages in allergic and nonallergic black and white individuals. J Allergy Clin Immunol 1985, 75:651-658.

19. Stoy PJ, Roitman-Johnson B, Walsh G, Gleich GJ, Mendell N, Yunis E, Blumenthal MN: Aging and serum immunoglobulin E levels, immediate skin tests, RAST. J Allergy Clin Immunol 1981, 68:421-426.

20. Broadfield E, McKeever TM, Scrivener S, Venn A, Lewis SA, Britton J: Increase in the prevalence of allergen skin sensitization in successive birth cohorts. J Allergy Clin Immunol 2002, 109:969-974.

21. Salo PM, Calatroni A, Gergen PJ, Hoppin JA, Sever ML, Jaramillo R, Arbes SJ, Zeldin DC: Allergy-related outcomes in relation to serum IgE: results from the national health and nutrition examination survey 2005-2006. J Allergy Clin Immunol 2011, 127:1226-1235. e1227.

22. Jarvis D, Luczynska C, Chinn S, Potts J, Sunyer J, Janson C, Svanes C, Künzli N, Leynaert B, Heinrich J, Kerkhof M, Ackermann-Liebrich U, Antó JM, Cerveri I, de Marco R, Gislason T, Neukirch F, Vermeire P, Wjst M, Burney P: Change in prevalence of $\lg E$ sensitization and mean total $\lg E$ with age and cohort. J Allergy Clin Immunol 2005, 116:675-682.

23. Miller MR, Hankinson J, Brusasco V, Burgos F, Casaburi R, Coates A, Crapo R, Enright $P$, van der Grinten $C P$, Gustafsson $P$, Jensen $R$, Johnson DC, MacIntyre N, McKay R, Navajas D, Pedersen OF, Pellegrino R, Viegi G, Wanger J, ATS/ERS Task Force: Standardisation of spirometry. Eur Respir J 2005, 26:319-338.

24. 邓: Standardization of spirometry, 1994 update. American thoracic society. Am J Respir Crit Care Med 1995, 152:1107-1136.

25. Bateman ED, Hurd SS, Barnes PJ, Bousquet J, Drazen JM, FitzGerald M, Gibson P, Ohta K, O'Byrne P, Pedersen SE, Pizzichini E, Sullivan SD, Wenzel $\mathrm{SE}, \mathrm{Zar} \mathrm{HJ}$ : Global strategy for asthma management and prevention: GINA executive summary. Eur Respir J 2008, 31:143-178.

26. Barbee RA, Halonen M, Kaltenborn W, Lebowitz M, Burrows B: A longitudinal study of serum IgE in a community cohort: correlations with age, sex, smoking, and atopic status. J Allergy Clin Immunol 1987, 79:919-927.
27. Jarvis D, Chinn S, Luczynska C, Burney P: The association of smoking with sensitization to common environmental allergens: results from the European community respiratory health survey. J Allergy Clin Immunol 1999, 104:934-940.

28. Warren CP, Holford-Strevens V, Wong C, Manfreda J: The relationship between smoking and total immunoglobulin E levels. J Allergy Clin Immunol 1982, 69:370-375.

29. Nagasaki T, Matsumoto H, Nakaji H, Niimi A, Ito I, Oguma T, Muro S, Inoue H, Iwata T, Tajiri T, Kanemitsu Y, Mishima M: Smoking attenuates the agerelated decrease in IgE levels and maintains eosinophilic inflammation. Clin Exp Allergy 2013, 43:608-615.

30. Matricardi PM, Bockelbrink A, Grüber C, Keil T, Hamelmann E, Wahn U, Lau S: Longitudinal trends of total and allergen-specific lgE throughout childhood. Allergy 2009, 64:1093-1098.

31. Carsin AE, Zock JP, Jarvis D, Basagaña X, Heinrich J, Toren K, Janson C, Anto $J M$, Sunyer J: Serum total immunoglobulin $E$ is a surrogate of atopy in adult-onset asthma: a longitudinal study. Int Arch Allergy Immunol 2013, 160:387-392.

32. Denning DW, Pashley C, Hartl D, Wardlaw A, Godet C, Del Giacco S, Delhaes $L$, Sergejeva S: Fungal allergy in asthma-state of the art and research needs. Clin Transl Allergy 2014, 4:14.

33. Jaakkola MS, leromnimon A, Jaakkola JJ: Are atopy and specific lgE to mites and molds important for adult asthma? J Allergy Clin Immunol 2006, 117:642-648.

doi:10.1186/s12931-014-0144-8

Cite this article as: Tanaka et al:: Longitudinal increase in total IgE levels in patients with adult asthma: an association with poor asthma control. Respiratory Research 2014 15:144.

\section{Submit your next manuscript to BioMed Central and take full advantage of:}

- Convenient online submission

- Thorough peer review

- No space constraints or color figure charges

- Immediate publication on acceptance

- Inclusion in PubMed, CAS, Scopus and Google Scholar

- Research which is freely available for redistribution

Submit your manuscript at www.biomedcentral.com/submit
C Biomed Central 